\title{
Comprehensive, research-based interviewing guidelines in general practice settings
}

\author{
ROBERT C. SMITH
}

\begin{abstract}
Medical interviewing has evolved considerably during the last 35-50 years. Nowhere has progress been greater than with the articulation of the interview's endpoint, the biopsychosocial model (Engel, $1977 b ; 1980)$. Interviewers collect personal information and physical symptoms from the patient and, then, synthesize these data to produce a biopsychosocial description - the patient's story. We generally recognize the systems-based biopsychosocial model as the gold standard for understanding the patient from a scientific as well as humanistic vantage point (Simpson, 1963; von Bertalanffy, 1968; Lorenz, 1971; Brody, 1973; Welss, 1973; Bateson, 1979; Mayr, 1982). Extensive research supports this position.
\end{abstract}

\section{THE BIOPSYCHOSOCIAL MODEL IS ONLY AS GOOD AS THE PATIENT-CENTERED METHOD USED TO OPERATIONALIZE IT}

The biopsychosocial model has not helped as much as once hoped in fostering a humanistic, patient-centered medicine - where patient-centered interviewing practices must be implemented to identify relevant personal and symptom data and to establish an effective provider-patient relationship. The model simply tells us what information we need about the patient without telling us how to acquire it (Smith, $1996 ; 1997)$. At this time, we understand the biopsychosocial model far better than the patient-centered interviewing process needed to operationalize it.

Troublesome in this respect is that many view patient-centered interviewing as time-consuming and

Indirizzo per la corrispondenza: Dr. R.C. Smith, B306 Clinical Center, East Lansing, MI 48824 (USA).

Fax: + 1-517-432-1326

E-mail: smithrr@pilot.msu.edu difficult to learn, greatly impeding acceptance and implementation. To be certain, mastery of interviewing requires more than the intellectual understanding that suffices with the biopsychosocial model. Experiential learning about usually unfamiliar skills must occur but, as we have shown (Smith et al., 1998), this is not an insurmountable task.

Because patient-centered interviewing has progressed more slowly, the original promise of the biopsychosocial model has not been met. In my opinion, this failure occurred, not for a fault in the model but for failure to develop user-friendly and comprehensive patient-centered methods to effectively and efficiently operationalize it. To the extent patient-centered methods are ineffective, the biopsychosocial model remains only a theoretical construct of little practical importance in caring for individual patients on a daily basis. The solution is not to devise new models but, rather, to improve our patient-centered method.

\section{PATIENT-CENTERED INTERVIEWING CAN TRANSFORM MAINSTREAM MEDICINE AND VICE VERSA}

Many recent advances have improved the patientcentered method considerably and include identification of: a curriculum (Lipkin et al., 1984; Kem et al., 1989; Roter et al., 1990; Smith et al., 1991; 1998; Langewitz et al., 1998), a structure of the interview (Lipkin, 1987), the three functions of the interview (Bird \& Cohen-Cole, 1991; Cohen-Cole, 1991; Lazare et al., 1995), the actual process of the interview (Rogers, 1951; Lazare et al., 1975; Lipp, 1977; McWhinney, 1981; 1989; Levenstein et al., 1986; 1989; Lipkin, 1987; Smith \& Hoppe, 1991; Smith, 1996), critical features of the doctor-patient relationship (Engel, 1977a; Relser \& Schroder, 1980; Brody, 1982; Freeling, 1983; Quill, 1983; 1989; Cassel, 1985; 
Lazare et al., 1987; Novack, 1987; Roter et al., 1987; Hall et al., 1988; Suchman \& Matthews, 1988; Kaplan et al., 1989; Smith, 1996), and the impact of physician self-awareness on the interview (Johnson, 1979; Gorlin \& Zucker, 1983; Smith, 1984; 1986; 1995; Smith \& Zimny, 1988). Central to this success has been research that anchored interviewing to what actually is effective (Rogers, 1951; Korsch et al., 1968; Freemon et al., 1971; Ley et al., 1976; Kleinman et al., 1978; Carroll \& Monroe, 1979; Cox et al., 1981a, b; 1988; Hopkinson et al., 1981; Carter et al., 1982; Burack \& Carpenter, 1983; Beckman \& Frankel, 1984; Frankel, 1984; Mishler, 1984; Stewart, 1984; Putnam et al., 1985; 1988; Maguire et al., 1986; Francis et al., 1987; Kleimnan, 1987; Roter et al., 1987; Hall et al., 1988; Roter, 1989; Smith et al., 1995a, b; 1998; Langewitz et al., 1998). In teaching interviewing to students, housestaff, faculty, practitioners, nurse practitioners, and physician assistants during the last 20 years, I have observed remarkable improvement in developing a relationship and obtaining the patient's personal story, a refreshing contrast to the old isolated focus on organic disease.

Unhappily, in spite of progress in patient-centered medicine, the "old school» favoring an isolated doctor-centered interview aimed at making just a disease diagnosis still holds sway, continuing to bind modem medicine to the biomedical (biotechnical) model which pays little attention to the personhood of the patient. Indeed, many medical schools still attend poorly to training in interviewing (Novack et al., 1993), many interviewing texts neither reference «patient-centered" nor evince its practice in their recommendations, and many residencies don't effectively broach the topic (Merkel et al., 1990; Parrino \& Kern, 1994; Sullivan et al., 1996) - all of which encourage and reinforce an isolated doctor-centered interviewing approach. And all this in light of the well documented benefits from integrating patientcentered and doctor-centered interviewing methods. For example, it has been shown through rigorous research that using a patient-centered method improves patient satisfaction and compliance (Roter et al., 1987; Hall et al., 1988), and health outcomes (Egbert et al., 1964; Shear et al., 1983; Kaplan et al., 1989). Nor does anyone dispute that patient-centered medicine is more humane for the doctor as well as for the patient (Roter et al., 1987; Hall et al., 1988; Suchman \& Matthews, 1988). Or that doctor-shopping and litigation are reduced (Kasteler et al., 1976; Huycke \& Huycke, 1994).
Why is it, then, that biomedicine and its educators have not fully embraced a patient-centered interviewing approach? We make a mistake, in my opinion, to blame this impasse on psychological resistance, which we sometimes hear as an explanation. After all, mainstream medicine has quite avidly accepted the well known and frequently taught biopsychosocial model. Instead, I propose that we take more seriously the legitimate educational and scientific requirements of our mainstream colleagues. To ignore them will not only diminish the quality of our own products, but almost certainly will continue to interfere with acceptance of our patient-centered principles by mainstream medicine.

To cite two specific examples, until recently, there had been no publication of a complete, step-by-step method for patient-centered interviewing, perhaps the most complex task in all clinical medicine. This ignores the recommendations of many mainstream as well as patient-centered educators for developing detailed, behaviorally-defined methods/models for teaching complex topics of any sort (Carroll \& Monroe, 1980; Flaherty, 1985; Schunk, 1985; Stewart \& Roter, 1989; McKeachie et al., 1990; Maguire, 1992; Feinstein, 1994; Westberg \& Jason, 1994; Kurtz \& Silvennan, 1996). Secondly, interviewing recommendations in texts and elsewhere have had little or no data to support them, again ignoring a central tenet of modern, evidence-based medicine (Sackett $e t$ al., 1997). Understood this way, when we recommend and use nonsystematic, nonresearch-based interviewing methods, we inadvertently flaunt the valuable principles of the very biomedical and educational people we need to convince.

\section{BEGINNING EFFORTS TO ADDRESS THE PROBLEM}

In grappling with this problem, our group was fortunate in two respects. First, a rich patient-centered literature existed. What remained to be done was to put all the pieces together into one step-bystep, complete method - a daunting task which, likely, no one previously had had sufficient time and funding to do. Second, we encountered the Fetzer Institute (Kalamazoo, MI). Fetzer provided the funding and moral support that allowed us to proceed with a previously impossible task: 1) synthesizing a detailed, behaviorally-defined patient-centered interviewing method that described, step-by-step, how one proceeded throughout the entire interview 
and 2) testing the method rigorously in a randomized controlled trial. We were indeed privileged to be able to identify a comprehensive and detailed patient-centered interviewing method (Smith, 1996), one not unlike what we suspect others would have identified given the unique opportunity. In turn, we showed that the method was effective (Smith et al., 1995a, b; 1998).

The method. The new, detailed patient-centered interviewing method consists of steps $1-5$, with some 25 substeps, which immediately precede steps 6-12, the standard doctor-centered interview. Each substep is behaviorally-defined, the behaviors are ordered and sequenced, and priorities within the interview are identified. The patient-centered interviewing method is learned easily. Most students and physicians can effectively conduct the steps and substeps after two teaching sessions. Although taking longer while learning it, the five steps can be completed with most patients in no more than 3-5 minutes by the completion of training, meeting our objectives that the patient-centered interview must be efficient.

There is one caveat. This method is more detailed and specific than earlier forms of patient-centered communication. Learners have to work harder to learn this more detailed material, especially at the outset when they learn the 5 steps and 25 substeps. They have not complained or resisted and, rather, have been excited and pleased with their results. Teachers also indicate that the method is «more substantive," and that this is corroborated by their students who previously complained that interviewing training was «just boring repetition of the same old stuff;" these students report now that training is "tangible» rather than diffuse. Learners who have had previous interviewing training comment that they have understood for the first time how the many skills fit together, that they value the efficiency, and that they have more confidence.

Concerns about detailed methods. Some teachers who had not used the 5-step method were understandably concerned that any specific method could destroy the individuality of patient and interviewer alike, that the uniqueness of the patient and interviewer would be lost in a slavish repetition of a specified series of questions (Gruen, 1986). In my experience with patient-centered interviewer teachers, this anxiety has been the major impediment to developing and implementing comprehensive, detailed interviewing methods. While providing explicit guidelines and signposts throughout the interview, the 5step method remains quite flexible and does not pre- scribe specific questions or rigid routines. Those teachers using the method report that it fosters both the interviewer's and the patient's individuality greatly enhancing the humanistic dimension for each, as our research also showed (Smith et al., 1995a, b, 1998). Rather than a rote procedure, the method simply brings a discipline and complete guidelines for how one proceeds throughout the interview, not unlike physicians' use of guidelines when first learning to perform the physical examination. The educational literature reports similarly that explicit behaviorally-defined methods and models for complex tasks not only allow learners to be more effective and confident but also more uniquely themselves when faced with complex, otherwise nearly insurmountable tasks (Carroll \& Monroe, 1980; Flaherty, 1985; Schunk, 1985; Stewart \& Roter, 1989; McKeachie et al., 1990; Maguire, 1992; Feinstein, 1994; Westberg \& Jason, 1994; Kurtz \& Silverman, 1996).

The research. The randomized controlled evaluation, in brief, showed that experiential training with this 5 -step patient-centered interviewing method produced striking improvement in first year residents' knowledge, attitudes, and skills conceming patientcentered interviewing (Smith et al., 1995a, b; 1998). We also found a consistent trend towards improvement in the patients of trained residents: increased satisfaction and decreases in somatic complaints and social dysfunction. The key change in residents' attitudes was an increase in self-efficacy, or self-confidence, in using patient-centered interviewing skills. Bandura and others have shown that self-efficacy is a key predictor of actual performance of skills being taught (Bandura, 1977; 1986; Schunk 1985; McKeachie et al., 1990; Tresolini \& Stritter, 1992). In addition, we demonstrated very significant changes on all eleven scales we used to evaluate patient-centered interviewing skills, the evaluations deriving from real patients as well as simulated patients. We concluded that trained residents, compared to control residents, exhibited much better relationships and patient-centered interviewing skills and that the trained residents were effectively and efficiently replicating the new, 5-step patient-centered interviewing method we had taught them. Our experience with medical students, graduate physicians, nurse practitioners, and physician assistants reveals that discipline and level of training have no impact on ability to learn and use the 5-step interviewing method, and that the method is applicable 
for all new learners; we studied first year residents because that was the focus of funding.

\section{SCIENCE AND THE PATIENT}

To put systematic, comprehensive, and researchbased patient-centered interviewing (of the type described here or other types) into broader context, recall Feinstein's and others' laments: modem medicine has no scientific identity, has no intellectual base, and is nothing more than a potpourri of material imported from other disciplines such as, for example, each basic science, epidemiology, biostatistics, sociology, economics, and anthropology (Feinstein, 1987). This troubles many because none of these disciplines has the personal dimension of the medically ill patient as a focus. In fact, few deal at all with patients! We thus have the paradox that medicine, where the patient is paramount, has come to stand on a nonclinical base (Feinstein, 1987). Of course, no one advocates scrapping these dimensions which have contributed so much to the successes of modern medicine. Rather, the plea is to bring the patient back into medicine, as the hub of medicine with spokes radiating out to each component discipline. Not surprisingly, a nonclinical base has prevented medicine from most meaningfully addressing the personal issues of greatest interest to the patient: treatment, prognosis, and other decisions in patient care (Feinstein, 1983a; 1987, 1994; Cassidy, 1994).

Engel, Feinstein, and McWhinney, among many, have challenged clinicians to better define the science of medicine around the personhood of the patient if medicine is to progress as a science. To do this, we are encouraged to develop better methods and better models (Engel, 1977a, b; 1987; McWhinney, 1981; 1989; Feinstein, 1983a, b, e, d; 1987).

A patient-centered interviewing method that is behaviorally-defined, describes a complete interview, and is detailed can extend and refine the more general patient-centered methods previously espoused by educators, humanists, and scholars (Rogers, 1951; Lazare et al., 1975; Lipp, 1977; McWhinney, 1981; 1989; Levenstein et al., 1986; 1989). As students, physicians, nurse practitioners, and physician assistants use a method that is more complete and specific, they will obtain more data uniquely reflecting the individual patient and form better relationships. This, in turn, allows them to synthesize a more accurate biopsychosocial description of the patient with respect to biomedical (disease) as well as psychosocial data; i.e., dis- ease diagnosis and management and humanistic practices will be enhanced. The improved method thus better «operationalizes» the biopsychosocial model and makes it more applicable and practical on a daily basis with individual patients. As the biopsychosocial model becomes more specific to the individual patient, it becomes more credible in establishing a base for medicine in general system theory (Simpson, 1963; von Bertalanffy, 1968; Lorenz, 1971; Brody, 1973; Weiss, 1973; Bateson, 1979; Mayr, 1982). Put another way, a systematic, complete patient-centered interviewing method helps us toward a key objective (Foss \& Rothenberg, 1987): that we find a strategy that «treats the individual patient in the context of his or her mutually interacting 'biocultural' identity.»

For these improvements in our guiding patientcentered method and biopsychosocial model to have maximum impact, however, we are advised that they must also have a strong research base if patient-centered interviewing is to become truly scientific (Inui \& Carter, 1985). That is, if we are to evolve as a scientific discipline, good ideas will be viewed as hypotheses requiring empirical support. Rigorously applying an experimental approach to proposed comprehensive methods will make our discipline more scientific as well as more humanistic.

\section{CONCLUSION}

As we develop systematic, comprehensive, and research-based methods in patient-centered communication, we will not only improve the scientific and humanistic quality of our product, but we also will have a better chance to overcome current objections to our integration into mainstream medicine. If this exciting prospect for the future occurs, all of medicine could someday be characterized by a transformed clinical method (McWhinney, 1989). The patient-centered interviewing method discussed here is simply an example of this direction and but one very small step in making the requisite paradigm shift (Kuhn, 1962).

\section{REFERENCES}

Bandura A. (1977). Self-efficacy: toward a unifying theory of behavioral change. Psychological Review 84, 191-215.

Bandura A. (1986). Social Foundations of Thought and Action. Prentice-Hall: Englewood Cliffs, NJ.

Bateson G. (1979). Mind and Nature. Bantam Books: New York. Beckman H.B. \& Frankel R.M. (1984). The effect of physician be- 
havior on the collection of data. Annals of Internal Medicine 101, 692-696.

Bird J. \& Cohen-Cole S.A. (1991). The three-function model of the medical interview: an educational device. In Models of Teaching Consultation-Liaison Psychiatry (ed. M. Hale). Karger: Basel.

Brody H. (1973). The systems view of man: implications for medicine, science, and ethics. Perspective of Biological Medicine 17, 71-92.

Brody H. (1982). The lie that heals: the ethics of giving placebos. Annals of Internal Medicine 97, 112-118.

Burack R.C. \& Carpenter R.R. (1983). The predictive value of the presenting complaint. Journal of Family Practice 16, 749-754.

Carroll J.G. \& Monroe J. (1979). Teaching medical interviewing: a critique of educational research and practice. Journal of Medical Education 54, 498-500.

Carroll J.G. \& Monroe J. (1980). Teaching clinical interviewing in the health professions - a review of empirical research. Evaluation Health Professions 3, 21-45.

Carter W.B., Inui T.S., Kukull W.A. \& Haigh V.H. (1982). Outcome-based doctor-patient interaction analysis. II. Identifying effective provider and patient behavior. Medical Care 20, 550566.

Cassel E.J. (1985). Talking with Patients. Vols. 1 and 2. MIT Press: Cambridge.

Cassidy C.M. (1994). Unraveling the ball of string: reality, paradigms, and the study of alternative medicine. Advances 10,531.

Cohen-Cole S.A. (1991). The Medical Interview: The Three Function Approach. St. Mosby-Year Book: Louis.

Cox A., Holbrook D. \& Rutter M. (1981a). Psychiatric interviewing techniques VI. experimental study: eliciting feelings. British Journal of Psychiatry 139, 144-152.

Cox A., Rutter M. \& Holbrook D. (1981b). Psychiatric interviewing techniques V. Experimental study: eliciting factual information. British Journal of Psychiatry 139, 29-37.

Cox A., Rutter M. \& Holbrook D. (1988). Psychiatric interviewing techniques. A second experimental study: eliciting feelings. British Journal of Psychiatry 152, 64-72.

Egbert L.D., Battit G.E., Welch C.E. \& Bartlett M.K. (1964). Reduction of postoperative pain by encouragement and instruction of patients. A study of doctor-patient rapport. New England Journal of Medicine 270, 825-827.

Engel G.L. (1977a). The care of the patient: art or science? Johns. Hopkins Medical Journal 140, 222-232.

Engel G.L. (1977b). The need for a new medical model: a challenge for biomedicine. Science 196, 129-136.

Engel G.L. (1980). The clinical application of the biopsychosocial model. American Journal of Psychiatry 137, 535-544.

Engel G.L. (1987). Physician-scientists and scientific physicians. American Journal of Medicine 82, 107-111.

Feinstein A.R. (1983a). An additional basic science for clinical medicine: I. the constraining fundamental paradigms. Annals of Internal Medicine 99, 393-397.

Feinstein A.R. (1983b). An additional basic science for clinical medicine: II. The limitations of randomized trials. Annals of Internal Medicine 99, 544-550.

Feinstein A.R. (1983c). An addifional basic science for clinical medicine: III. The challenges of comparison and measurement. Annals of Internal Medicine 99, 705-712.

Feinstein A.R. (1983d). An additional basic science for clinical medicine: IV. The development of clinimetrics. Annals of Internal Medicine 99, 843-848.
Feinstein A.R. (1987). The intellectual crisis in clinical science: medaled models and muddled mettle. Perspectives in Biology and Medicine 30, 215-230.

Feinstein A.R. (1994). Clinical Judgement revisited: the distraction of quantitative models. Annals of Internal Medicine 120, 799805.

Flaherty J.A. (1985). Education and evaluation of interpersonal skills. In: The Interpersonal Dimension in Medical Education (ed. A.G. Rezler and J.A. Flaherty). Springer Publishing Company: New York.

Foss L. \& Rothenberg K. (1987). The Second Medical Revolution: From Biomedicine to Infomedicine. Shambhala: Boston.

Francis V., Korsch B.M. \& Morris M.F. (1987). Gaps in doctorpatient communication: patients' response to medical advice. In Encounters Between Patients and Doctors (ed. J.D. Stoeckle). MIT Press: Cambridge.

Frankel R.M. (1984). From sentence to sequence: understanding the medical encounter through microinteractional analysis. $\mathrm{Di}$ scourse Process 7, 135-170.

Freeling P. (1983). The doctor-patient relationship in diagnosis and treatment. In Doctor-Patient Communication (ed. D. Pendleton and J. Hasler). Academic Press: Orlando.

Freemon B., Negrete V.F., Davis M. \& Korsch B.M. (1971). Gaps in doctor-patient communication: doctor-patient interaction analysis. Pediatric Research 5, 298-311.

Gorlin R. \& Zucker H.D. (1983). Physicians' reactions to patients: a key to teaching humanistic medicine. New England Journal of Medicine 308, 1059-1063.

Gruen A. (1986). The Betrayal of the Self-the Fear of Autonomy in Men and Women. Grove Press: New York.

Hall J.A., Roter D.L. \& Katz N.R. (1988). Meta-analysis of correlates of provider behavior in medical encounters. Medical Care 26, 657-675.

Hopkinson K., Cox A. \& Rutter M. (1981). Psychiatric interviewing techniques III naturalistic study: eliciting feelings. British Journal of Psychiatry 138, 406-415.

Huycke L.I. \& Huycke M.M. (1994). Characteristics of potential plaintiffs in malpractice litigation. Annals of Internal Medicine 120, $792-798$.

Inui T.S. \& Carter W.B. (1985). Problems and prospects for health services research on provider-patient communication. Medical Care 23, 521-538.

Johnson A.H. (1979). Assessing counselling skills and attitudes in family practice. Journal of Family Practice 9, 447-452.

Kaplan S.H., Greenfield S. \& Ware J.E. (1989). Impact of the doctor-patient relationship on the outcomes of chronic disease. In Communicating with Medical Patients (ed. M. Stewart and D. Roter). Sage Publications: London.

Kasteler J., Kane R.L., Olsen D.M. \& Thetford C. (1976). Issues underlying prevalence of "doctor-shopping» behavior. Journal of Health and Social Behavior 17, 328-339.

Kern D.E., Grayson M., Barker L.R., et al. (1989). Residency training in interviewing skills and the psychosocial domain of medical practice. Journal of General and Internal Medicine 4, 421431.

Kleinman A. (1987). Explanatory models in health-care relationships: a conceptual frame for research on family-based healthcare activities in relation to folk and professional forms of clinical care. In Encounters Between Patients and Doctors (ed. J.D. Stoeckle). MIT Press: Cambridge.

Kleinman A., Eisenberg L. \& Good B. (1978). Culture, illness and care-Clinical lessons from anthropologic and cross-culture research. Annals of Internal Medicine 88, 251-258. 
Korsch B.M., Gozzi E.K. \& Francis V. (1968). Gaps in doctor-patient communication-I. Doctor-patient interaction and patient satisfaction. Pediatrics 42, 855-871.

Kuhn T. S. (1962). The Structure of Scientific Revolutions (2nd ed.). University of Chicago Press: Chicago.

Kurtz S.M. \& Silverman J.D. (1996). The Calgary-Cambridge Referenced Observation Guides: an aid to defining the curriculum and organizing the teaching in communication training programmes. Medical Education 30, 83-89.

Langewitz W.A., Eich P., Kiss A. \& Wossmer B. (1998). Improving communication skills. A randomized controlled behaviorally oriented intervention study for residents in internal medicine. Psychosomatic Medicine 60, 268-276.

Lazare A., Eisenthal S. \& Wasserman L. (1975). The customer approach to patient hood: attending to patient requests in a walk-in clinic. Archives of General Psychiatry 32, 552-558.

Lazare A., Eisenthal S., Frank A. \& Stoeckle J.D. (1987). Studies on a negotiated approach to patient hood. In Encounters Between Patients and Doctors (ed. J.D. Stoeckle). MIT Press: Cambridge.

Lazare A., Putnam S. \& Lipkin M. (1995). Three functions of the medical interview. In The Medical Interview (ed. M. Lipkin, S. Putnam and A. Lazare). Springer-Verlag: New York.

Levenstein J.H., McCracken E.C., McWhinney I.R., Stewart M.A. \& Brown J.B. (1986). The patient-centered clinical method. 1. A model for the doctor-patient interaction in family medicine. Journal of Family Practice 3, 24-30.

Levenstein J.H., Brown J.B., Weston W.W., Stewart M., McCracken E.C. \& McWinney I. (1989). Patient centered clinical interviewing. In Communicating with Medical Patients (ed. M. Stewart and D. Roter). Sage Publications: London.

Ley P., Whitworth M.A., Skilbeck C.E., Woodwaard R., Pinsent R.J., Pike L.A., et al. (1976). Improving doctor-patient communication in general practice. Journal of the Royal College of General Practitioners 26, 720-724.

Lipkin M. (1987). The medical interview and related skills. In $O f-$ fice Practice of Medicine (ed. W.T. Branch). W.B. Saunders: Philadelphia.

Lipkin M., Quill T.E. \& Napodano R.J. (1984). The medical interview: a core curriculum for residencies in internal medicine. Annals of Internal Medicine 100, 277-284.

Lipp M.R. (1977). Respectful Treatment. The Human Side of Medical Care. Harper and Row: New York.

Lorenz K. (1971). Knowledge, beliefs, and freedom. In Hierarchically Organized Systems in Theory and Practice (ed. P.A. Weiss). Hafner: New York.

Maguire P. (1 992). Teaching interviewing skills to medical students. Medical Encounter 8, 4-5.

Maguire P., Fairbaim S. \& Fletcher C. (1986). Consultation skills of young doctors: 1 . Benefits of feedback training in interviewing as students persist. British Medical Journal 292, 1573 1578.

Mayr E. (1982). The Growth of Biological Thought. Diversity, Evolution, and Inheritance. Belknap Press of Harvard University Press: Cambridge, MA.

McKeachie W.J., Pintrich P.R., Lin Y., Smith D.A.F. \& Shanna R. (1990). Teaching and Learning in the College Classroom (2nd ed.). Regents of the University of Michigan, Suite 2400, School of Education Bldg.: Ann Arbor, MI.

McWhinney I. (1981). An Introduction to Family Medicine. Oxford University Press: New York.

McWhinney I. (1989). The need for a transformed clinical method.
In Communicating with Medical Patients (ed. M. Stewart and D. Roter). Sage Publications: London.

Merkel W.T., Margolis R.B. \& Smith R.C. (1990). Teaching humanistic and psychosocial aspects of care: current practices and attitudes. Journal of General and Internal Medicine 5, 3441.

Mishler E.G. (1984). The Discourse of Medicine. Ablex Publishing Corp: Norwood, NJ.

Novack D.H. (1987). Therapeutic aspects of the clinical encounter. Journal of General and Internal Medicine 2, 346-355.

Novack D.H., Volk G., Drossman D.A. \& Lipkin M. Jr. (1993). Medical interviewing and interpersonal skills teaching in US medical schools. Journal of the American Medical Association 269, 2101-2105.

Parrino T.A. \& Kem D.C. (1994). The alumni survey as an instrument for program evaluation in internal medicine. Journal of General and Internal Medicine 9, 92-95.

Putnam S.M., Stiles W.B., Casey-Jacob M. \& James S.A. (1985). Patient exposition and physician explanation in initial medical interviews and outcomes of clinic visits. Medical Care 23, 7483.

Putnam S.M., Stiles W.B., Casey-Jacob M. \& James S.A. (1988). Teaching the medical interview. Journal of General and Internal Medicine 3, 38-47.

Quill T.E. (1983). Partnerships in patient care: a contractual approach. Annals of Internal Medicine 98, 228-234.

Quill T.E. (1989). Recognizing and adjusting to barriers in doctor patient communication. Annals of Internal Medicine 111, 5157.

Reiser D.E. \& Schroder A.K. (1980). Patient Interviewing. The Human Dimension. Williams and Wilkins: Baltimore.

Rogers C.R. (1951). Client-Centered Therapy. Houghton Mifflin Company: Boston.

Roter D. (1989). Which facets of communication have strong effects on outcome. A meta-analysis. In Communicating with Medical Patients (ed. M. Stewart and D. Roter). Sage Publications: London.

Roter D.L., Hall J.A. \& Katz N.R. (1987). Relations between physicians' behaviors and analogue patients' satisfaction, recall, and impressions. Medical Care 25, 43 7-451.

Roter D.L., Cole K.A., Kem D.E., Barker L.R. \& Grayson M. (1990). An evaluation of residency training in interviewing skills and the psychosocial domain of medical practice. Journal of General and Internal Medicine 5, 347-354.

Sackett D.L., Richardson W. S., Rosenberg W. \& Haynes R.B. (1997). Evidence-based Medicine. How to Practice and Teach $E B M$. Churchill Livinsgtone: New York.

Schunk D.H. (1985). Self-efficacy and classroom leaming. Psychology in the Schools 22, 208-223.

Shear C.L., Gipe B.T., Mattheis J.K. \& Levy M.R. (1983). Provider continuity and quality of medical care-a retrospective analysis of prenatal and perinatal outcome. Medical Care 21, 1204-1210.

Simpson G.G. (1963). Biology and the nature of science. Science $139,81-88$.

Smith R.C. (1984). Teaching interviewing skills to medical students: the issue of 'countertransference'. Journal of Medical Education 59, 582-588.

Smith R.C. (1986). Unrecognized responses by physicians during the interview. Journal of Medical Education 61, 982-984.

Smith R.C. (1995). Use and management of physicians' feelings during the interview. In The Medical IIterview (ed. M. Lipkin, S.M. Putnam and A. Lazare). Springer-Verlag: New York. 
Smith R.C. (1996). The Patient's Story. Integrated Patient-Doctor Interviewing. Little, Brown and Company: Boston.

Smith R.C. (1997). La Storia del Paziente. Un Approccio Integrato All'Intervista Medica (Ed. it. a cura di Christa Zimmermann). Il Pensiero Scientifico Editore: Roma.

Smith R.C. \& Hoppe R.B. (1991). The patient's story: integrating the patient- and physician-centered approaches to interviewing. Annals of Internal Medicine 115, 470-477.

Smith R.C. \& Zimny G. (1988). Physicians' emotional reactions to patients. Psychosomatics 29, 392-397.

Smith R.C., Osbom G., Hoppe R.B., Lyles J.S., Van Egeren L., Henry R., Sego D., Alguire P. \& Stoffelmayr B. (1991). Efficacy of a one-month training block in psychosocial medicine for residents: a controlled study. Journal of General and Internal Medicine 6, 535-543.

Smith R.C., Lyles J.S., Mettler J.A., Marshall A.A., Van Egeren L.F., Stoffelmayr B.E., Osborn G.G. \& Shebroe V. (1995a). A strategy for improving patient satisfaction by the intensive training of residents in psychosocial medicine: a controlled, randomized study. Academic Medicine 70, 729-732.

Smith R.C., Mettler J.A., Stoffelmayr B.E., Lyles J.S., Marshall A.A., Van Egeren L.F., Osbom G.G. \& Shebroe V. (1995b). Improving residents' confidence in using psychosocial skills. Journal of General and Internal Medicine 10, 315-320.

Smith R.C., Lyles J.S., Mettler J., Stoffelmayr B.E., Van Egeren L.F., Marshall A.M., Gardiner J.C., Maduschke K.M., Stanley J.M., Osborn G.G., Shebroe V. \& Greenbaum R.B. (1998). The effectiveness of an intensive training for residents in interviewing. A randomized, controlled study. Annals of Internal Medicine 128, 118-126.

Stewart M.A. (1984). What is a successful doctor-patient interview? A study of interactions and outcomes. Social Science and Medicine 2, 167-175.

Stewart M. \& Roter D. (1989). Conclusions. In Communicating with Medical Patients (ed. M. Stewart and D. Roter). Sage Publications: London.

Suchman A.L. \& Matthews D.A. (1988). What makes the patientdoctor relationship therapeutic? Exploring the connexional dimension of medical care. Annals of Internal Medicine 108, 125130.

Sullivan M.D., Cole S.A., Gordon G., Hahn S.R. \& Kathol R.G. (1996). Psychiatric training in medicine residencies. Current needs, practices, and satisfaction. General Hospital Psychiatry $18,95-101$.

Tresolini C.P. \& Stritter F.T. (1992). Medical students' development of self-efficacy in conducting patient education for health promotion: an analysis of learning experiences. Presented at the Annual Meeting of the American Educational Research Association, San Francisco, April, 1992.

von Bertalanffy L. (1968). General System Theory: Foundations, Development, Application (Revised ed.). George Braziller: New York.

Weiss P.A. (1973). The Science of Life: the Living System. A System for Living. Futura Publishing: Mount Kisco, NY.

Westberg J. \& Jason H. (1994). Teaching Creatively With Video: Fostering Reflection, Communication and Other Clinical Skills. Springer Publishing: New York. 